\title{
Pengaruh Work Family Conflict dan Stres Kerja terhadap Kinerja Karyawan pada PT. BPR Parthakencana Tohpati di Denpasar
}

\author{
Ni Wayan Ayu Trisnawati (1) \\ I Wayan Suartina ${ }^{(2)}$ \\ Ida Ayu Sasmita Dewi ${ }^{(3)}$ \\ ${ }^{(1)(2)(3)}$ Fakultas Ekonomi Bisnis dan Pariwisata Universitas Hindu Indonesia \\ e-mail: risna.ayu19@gmail.com \\ \begin{tabular}{|l|l|l|}
\hline Diterima: 3 Desember 2020 & Direvisi: 16 Desember 2020 & Disetujui: 30 Desember 2020 \\
\hline
\end{tabular}
}

\begin{abstract}
Performance is the result obtained by an organization, both the organization is profit oriented and non profit oriented which is generated during a period of time. The purpose of this study was to determine the effect of work family conflict and work stress on employee performance at PT. BPR Partakencana Tohpati in Denpasar. This research was conducted at PT. BPR Partakencana Tohpati, having its address at Jalan Gatot Subroto Timur No 49 Denpasar, Kesiman Kertalangu Village, Kesiman District, Denpasar Regency, Bali Province. The number of respondents taken was 50 employees, the sampling method was saturated. The data analysis techniques used were validity and reliability tests, classical assumption tests, multiple correlation analysis, multiple linear regression analysis, determination, $t$ test, and f test. Based on the analysis, it was found that work family conflict has a negative effect on employee performance, work stress has a positive and significant effect on employee performance, and simultaneously work family conflict and work stress have a positive and significant effect on employee performance at PT. BPR Partakencana Tohpati in Denpasar.
\end{abstract}

Keywords: work family conflict, job stress, employee performance

\begin{abstract}
ABSTRAK
Kinerja adalah hasil yang diperoleh suatu organisasi baik organisasi tersebut bersifat profit oriented dan non profit oriented yang dihasilkan selama satu periode waktu. Tujuan penelitian ini adalah untuk mengetahui pengaruh work family conflict dan stres kerja terhadap kinerja karyawan pada PT. BPR Partakencana Tohpati di Denpasar. Penelitian ini dilakukan pada PT. BPR Partakencana Tohpati yang beralamat di Jalan Gatot Subroto Timur No 49 Denpasar, Kelurahan Kesiman Kertalangu, Kecamatan Kesiman, Kabupaten Denpasar, Provinsi Bali. Jumlah responden yang diambil sebanyak 50 karyawan, metode sampling jenuh. Teknik analisis data yang digunakan adalah uji validitas dan reliabilitas, uji asumsi klasik, analisis korelasi berganda, analisis regresi linier berganda, determinasi, uji t, dan uji F. Berdasarkan hasil analisis ditemukan bahwa work family conflict berpengaruh negatif terhadap kinerja karyawan, stres kerja berpengaruh positif dan signifikan terhadap kinerja karyawan, serta secara simultan work family conflict dan stres kerja berpengaruh positif dan signifikan terhadap kinerja karyawan pada PT. BPR Partakencana Tohpati di Denpasar.
\end{abstract}

Kata kunci: work family conflict, stres kerja, kinerja karyawan 


\section{Pendahuluan}

Sedarmayanti (2011:260) mengungkapkan bahwa kinerja merupakan terjemahan dari performance yang berarti hasil kerja seorang pekerja, sebuah proses manajemen atau suatu organisasi secara keseluruhan, dimana hasil kerja tersebut harus dapat ditunjukkan buktinya secara konkrit dan dapat diukur (dibandingkan dengan standar yang ditentukan). Williams dan Anderson dalam Amelia (2010) menyatakan kinerja adalah in-role performance yang merupakan ukuran kinerja yang terkait langsung dengan pekerjaan seseorang. Menurut Bangun (2012:4), salah satu sumber daya organisasi yang memiliki peran penting dalam mencapai tujuannya adalah sumber daya manusia. Oleh karena itu, maka perlu adanya perhatian khusus agar kinerja karyawan dapat maksimal.

Wirawan (seperti yang dikutip dalam Hakim, 2016) menyatakan kinerja karyawan dipengaruhi oleh faktor intrinsik yaitu personal/individual dan faktor ekstrinsik yaitu kepemimpinan, sistem, tim, situasional, dan konflik. Konflik dilatarbelakangi oleh adanya ketidakcocokan atau perbedaan dalam hal nilai, tujuan, status, dan lain sebagainya. Hadirnya konflik dalam suatu perusahaan memang lebih banyak merupakan suatu gangguan terhadap keseimbangan situasi yang terjadi pada karyawan di perusahaan tersebut, yang akan mengganggu proses pelaksanaan aktivitas perusahaan ke arah tujuan akhir (Hakim, dkk. 2015).

Teori Greenhaus \& Beutell, dalam Razak, Omar dan Yunus, 2010 dan Susanti dan Ekayati, 2013, work family conflict dapat didefinisikan sebagai suatu konflik dimana terjadi ketidak seimbangan antara pekerjaan dan keluarga. Konflik pekerja-keluarga (work family conflict) yang didefinisikan sebagai bentuk konflik antar peran meliputi, tuntutan, waktu, dan ketegangan yang berasal dari pekerjaan mengganggu seseorang dalam melakukan tanggung jawabnya dalam keluarga (Netemeyer et al., dalam Novitasari 2015). Contoh Work Family Conflict yaitu, perusahaan mewajibkan karyawan untuk lembur pada hari libur nasional, menjadikan karyawan tersebut tidak bisa berkumpul dan menikmati libur bersama keluarganya (Mian et al..2012:698). Dalam penelitian yang dilakukan Kim \&Ling dikutip dari Soeharto (2010) menyatakan bahwa sikap yang negatif terhadap pekerjaan merupakan akibat dari work-family conflict.

Menurut Gaol (2014:65), stres kerja merupakan istilah yang merangkumi tekanan, beban, konflik, keletihan, panik, perasaan gemuruh, anxiety, kemurungan dan hilangnya daya. Stres kerja merupakan suatu keteganan yang dapat menciptakan ketidak seimbangan fisik dan psikis yang mempengaruhi emosi, kondisi dan proses berpikir seorang karyawan. Robbins (2015) menyatakan bahwa stres kerja merupakan suatu kondisi dimana seseorang dihadapkan pada keadaan yang menurutnya sangat penting yang membuat seorang individu secara alami menuntut dirinya sendiri 
untuk mendapatkan hal yang diinginkan dan dianggap penting.Menurut penelitian yang dilakukan oleh Ahmed (2013), stres kerja memiliki hubungan negatif dengan kinerja karyawan perbankan di Pakistan. Sari, dkk (2015) menyatakan bahwa stres dapat berpengaruh negatif terhadap kinerja karyawan pada PT. Bank Rakyat Indonesia (Persero Tbk cabang tuban) artinya bahwa semakin rendah stres dapat meningkatkan kinerja karyawan.

PT. Bank Perkreditan Rakyat Partakencana Tohpati (selanjutnya disebut Bank) didirikan berdasarkan Akta Notaris No. 145 Tanggal 27 Nopember 1992 yang dibuat dihadapan Notaris I Made Puryatma, SH di Denpasar dan telah disahkan oeleh Menteri Kehakiman Republik Indonesia dengan Surat Keputusan No.C2-10546.HT.01.01, Th. 1992 tanggal 28 Oktober 1992.PT. BPR Partakencana Tohpati adalah bank swasta yang berdiri pada tahun 1992 di Jalan Gatot Subroto Timur No 49 Denpasar Timur. PT. BPR Partakencana Tohpati sudah berdiri dari satu kantor cabang dan dua kantor kas yang menyebar di wilayah Kabupaten Denpasar, Badung dan Gianyar, PT. BPRPartakencana Tohpatiadalah salah satu perusahaan yang mengalami permasalahan mengenai tingginya tingkat work family conflict dan stres kerja pada karyawan. Maka dari itu PT. BPR Partakencana Tohpati adalah perusahaan yang cocok untuk dipilih menjadi lokasi penelitian.

Penelitian dari Wirakristama (2011), yang dilakukan pada karyawan yang sudah menikah menyatakan bahwa work family conflict berpengaruh terhadap kinerja karyawan. Sesuai dengan hasil penelitian yang dilakukan oleh Sudibya (2018) yang menjelaskan ketika work conflict family meningkat maka hal tersebut akan mempengaruhi peningkatan pada stres kerja karyawan. Berdasarkan penelitian yang dilakukan oleh Minarsih dan Hotma, (2011) menyatakan bahwa work family conflict dan stres kerja merupakan dua variabel yang saling berkaitan work family conflict akan menyebabkan seseorang mengalami stres kerja apabila tidak dapat mengelola konflik yangterjadi di lingkungan kerjanya, stres kerja terjadi karena seseorang dikejar untuk mencapai target tertentu. Tujuan penelitian ini adalah (1) untuk mengetahui pengaruh secara parsial work family conflict terhadap kinerja karyawan pada PT. BPR Partakencana Tohpati, (2) untuk mengetahui pengaruh secara parsial stres kerja terhadap kinerja karyawan pada PT. BPR Partakencana Tohpati, dan (3) untuk mengetahui pengaruh secara simultan work family conflict dan stres kerja terhadap kinerja karyawan pada PT. BPR Partakencana Tohpati.

\section{Telaah Literatur dan Kajian Pustaka}

\section{Kinerja Karyawan}

Kinerja adalah hasil yang diperoleh suatu organisasi baik organisasi tersebut bersifat profit oriented dan non profit oriented yang dihasilkan selama satu periode waktu (Fahmi, 2010:2). Berdasarkan Babin dan Boles dalam Maria D.T. (2012), mengartikan kinerja sebagai suatu 
tingkatan produktivitas karyawan secara individu yang dibandingkan dengan sesama karyawan atas beberapa pekerjaan yang berhubungan dengan perilaku (cara bekerja) dan hasil yang diterima. Secara lebih tegas Amstrong dan Baron yang dikutip oleh Fahmi (2010:6) mengatakan kinerja merupakan hasil pekerjaan yang mempunyai hubungan kuat dengan tujuan strategis organisasi, kepuasan konsumen dan memberikan kontribusi ekonomi.

\section{Work Family Conflict}

Konflik pekerjaan-keluarga (work-family conflict) menurut Frone et al.. dalam Wirakristama (2011) mendefinisikan sebagai konflik peran yang terjadi pada karyawan, dimana satu sisi ia harus melakukan pekerjaan di kantor dan di sisi lain harus memperhatikan keluarga secara utuh, sehingga sulit membedakan antara pekerjaan dengan keluarga. Menurut Greenhaus dan Beutell dalam Lilly, dkk (2016), adalah konflik antar peran yaitu peran dari pekerjaan dan tekanan dari keluarga saling bertentangan dalam beberapa hal.Maksudnya, bahwa melakukan peran dalam keluarga menjadi lebih sulit karena adanya gangguan dari peran dalam pekerjaan.

\section{Stres Kerja}

Menurut Ivancevich dan Matteson dalam Luthans (2015: 442), stres diartikan sebagai interaksi individu dengan lingkungan, tetapi kemudian diperinci lagi menjadi respon adaptif yang dihubungkan oleh perbedaan individu dan atau proses psikologi yang merupakan konsekuensi tindakan, situasi, atau kejadian eksternal (lingkungan) yang menempatkan tuntutan psikologis dan atau fisik secara berlebihan pada seseorang. Menurut Beehr dan Newman dalam Luthans (2014: 442) mendefinisikan stress kerja sebagai kondisi yang muncul dari interaksi antara menusia dan pekerjaan serta dikarakterisasikan oleh perubahan manusia yang memaksa mereka untuk menyimpang dari fungsi normal mereka. Bagian ini memuat teori utama dan/atau pendukung serta literatur-literatur sebelumnya yang terkait dengan penelitian, dan pengembangan hipotesis. Kajian pustaka dibuat secara naratif tanpa sub bab, hipotesis dibuat berdasarkan rumusan yang berasal dari hasil penelitian sebelumnya dan dibuat secara naratif. Tingginya tuntutan pekerjaan, kompleknya alur kerja, dan semakin tingginya tujuan organisasi menuntut setiap karyawan harus bekerja dengan cepat, fokus dan maksimal, dan menjadi sisi yang terus di hadapi oleh para karyawan, yang dapat mengakibatkan karyawan mengalami stres (Suryani dan Mahayoga, 2018).

Hipotesis yang diajukan dalam penelitian ini, H1. Diduga secara parsial work family conflict berpengaruh negatif terhadap kinerja karyawan pada PT. BPR Partakencana Tohpati, H2. Diduga secara parsial stres kerja berpengaruh positif dan signifikan terhadap kinerja karyawan pada PT. BPR Partakencana Tohpati, H3. Diduga secara simultan work family conflict dan stres kerja berpengaruh positif dan signifikan terhadap kinerja karyawan pada PT. BPR Partakencana Tohpati. 


\section{Metode Penelitian}

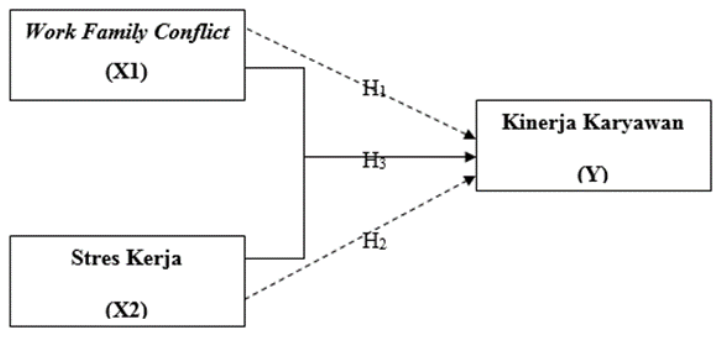

\section{Gambar 1 Kerangka Berpikir}

Populasi yang digunakan pada penelitian ini adalah seluruh karyawan PT. BPR Partakencana Tohpati di Denpasar yaitu sebanyak 50 orang. Teknik penentuan sampel dalam penelitian ini menggunakan metode sensus karena jumlah populasi dibawah 100 sehingga seluruh populasi dijadikan sampel, maka sampel penelitian yaitu sebanyak 50 karyawan. Untuk mendapatkan data yangrelevan, maka metode pengumpulan data yang digunakan antara lain observasi, wawancara, dokumentasi, studi kepustakaan, dan kuisioner. Dalam penelitian ini digunakan kuesioner dengan skala Likert. Menurut Sugiyono, (2011:93) skala Likert digunakan untuk mengukur sikap, pendapat dan persepsi seseorang atau sekelompok orang terhadap suatu fenomena.

Uji instrumen penelitian dilakukan dengan uji validitas untuk mengukur valid tidaknya suatu kuesioner serta seberapa kuat hubungan suatu variabel dengan variabel lainnya, dan uji reliabilitas adalah derajat ketepatan, ketelitian dan keakuratan yang ditunjukan oleh instrumen pengukuran. Uji asumsi klasik, yang terdiri atas uji normalitas, uji multikolinearitas, dan uji heteroskedastisitas. Analisis regresi linear berganda digunakan untuk mengetahui apakah terdapat pengaruh work family conflict dan stres kerja terhadap kinerja karyawan.

\section{Hasil Penelitian dan Pembahasan}

Berdasarkan Tabel 1, diketahui bahwa seluruh pernyataan memiliki koefisien korelasi yang lebih besar dari 0,30. Jadi dapat disimpulkan bahwa seluruh indikator telah memenuhi syarat validitas data dan reliabilitas data karenanilai Cronbach's Alpha menunjukkan nilai lebih dari 0,60. Karakteristik responden dalam penelitian ini dikelompokkan ke dalam empat kategori yaitu jenis kelamin, usia, masa kerja, dan posisi atau jabatan. Berdasarkan jenis kelamin, responden dalam penelitian ini terbagi menjadi 2 yaitu laki-laki sebanyak 22 orang $(44,00 \%)$ dan responden perempuan sebanyak 28 orang $(56,00 \%)$. Berdasarkan usia, dapat dinyatakan bahwa responden terbanyak memiliki usia antara 20-29 tahun yaitu sebanyak 20 orang $(40,00 \%)$ dan yang paling sedikit memiliki usia antara $>40$ tahun yaitu sebanyak 12 orang $(24,00 \%)$. Berdasarkan masa kerja, dapat dinyatakan bahwa responden terbanyak merupakan responden yang telah bekerja 
selama lebih dari 5 tahun yaitu sebanyak 25 orang $(50,00 \%)$ dan yang paling sedikit responden dengan masa bekerja kurang dari 1 tahun yaitu sebanyak 5 orang (10,00\%). Menurut pendidikan, dapat dinyatakan bahwa responden penelitian terbanyak sebagai staff sebanyak 38 orang atau 76,00\% tingkat pendidikan Sarjana , 7 orang atau 14.00\% tingkat pendidikan Diploma dan 5 orang atau $10.00 \%$ tingkat pendidikan SMA/SMK.

\section{Tabel 1. Hasil Uji Validitas dan Reliabilitas}

\begin{tabular}{|c|c|c|c|c|c|}
\hline \multirow[b]{2}{*}{ Variabel } & \multirow[b]{2}{*}{$\begin{array}{c}\text { Item } \\
\text { pernyataan }\end{array}$} & \multicolumn{2}{|c|}{ Validitas } & \multicolumn{2}{|c|}{ Reliabilitas } \\
\hline & & $\begin{array}{l}\text { Koefisien } \\
\text { Korelasi }\end{array}$ & Keterangan & $\begin{array}{c}\text { Cronbach's } \\
\text { Alpha }\end{array}$ & Keterangan \\
\hline \multirow{5}{*}{$\begin{array}{c}\text { Work } \\
\text { Family } \\
\text { Conflict }\end{array}$} & $\mathrm{X} 1.1$ & 0.704 & Valid & \multirow{5}{*}{0,646} & \multirow{5}{*}{ Reliabel } \\
\hline & $\mathrm{X} 1.2$ & 0.788 & Valid & & \\
\hline & X1.3 & 0.608 & Valid & & \\
\hline & X1.4 & 0.743 & Valid & & \\
\hline & X1.5 & 0.352 & Valid & & \\
\hline \multirow{4}{*}{$\begin{array}{l}\text { Stres } \\
\text { Kerja }\end{array}$} & $\mathrm{X} 2.1$ & 0.868 & Valid & \multirow{4}{*}{0,895} & \multirow{4}{*}{ Reliabel } \\
\hline & $\mathrm{X} 2.2$ & 0.875 & Valid & & \\
\hline & $\mathrm{X} 2.3$ & 0.897 & Valid & & \\
\hline & X2.4 & 0.848 & Valid & & \\
\hline \multirow{6}{*}{$\begin{array}{l}\text { Kinerja } \\
\text { Karyawan }\end{array}$} & Y.1 & 0.575 & Valid & \multirow{6}{*}{0,785} & \multirow{6}{*}{ Reliabel } \\
\hline & Y.2 & 0.567 & Valid & & \\
\hline & Y.3 & 0.798 & Valid & & \\
\hline & Y.4 & 0.852 & Valid & & \\
\hline & Y.5 & 0.603 & Valid & & \\
\hline & Y.6 & 0.765 & Valid & & \\
\hline
\end{tabular}

Sumber : data diolah, 2020

Berdasarkan Tabel 2, dapat dilihat bahwa seluruh penilaian katagori seluruh pernyataan kuesiner termasuk dalam katagori tidak setuju dengan skor rata-rata sebesar 1,93.

Tabel 2. Deskripsi Variabel Work Family Conflict

\begin{tabular}{|c|c|c|c|c|c|c|c|c|}
\hline \multirow[b]{2}{*}{ No } & \multirow[b]{2}{*}{ Item pernyataan } & \multicolumn{5}{|c|}{ Jawaban } & \multirow{2}{*}{$\begin{array}{l}\text { Rata- } \\
\text { rata } \\
\text { Skor }\end{array}$} & \multirow[b]{2}{*}{ Kategori Penilaian } \\
\hline & & 1 & 2 & 3 & 4 & 5 & & \\
\hline 1 & $\begin{array}{l}\text { Sikap yang kurang berkenan dari rekan kerja } \\
\text { dan atasan menyebabkan saya tertekan dan } \\
\text { terbebani sehingga terbawa ke dalam keluarga. }\end{array}$ & 26 & 8 & 4 & 6 & 6 & 2,16 & Tidak Baik \\
\hline 2 & $\begin{array}{l}\text { Tuntutan deadline dalam menyelesaikan } \\
\text { pekerjaan membuat saya tidak ada waktu untu } \\
\text { keluarga. }\end{array}$ & 23 & 8 & 9 & 4 & 6 & 2,24 & Tidak Baik \\
\hline 3 & $\begin{array}{l}\text { Saya tidak mempunyai cukup banyak waktu } \\
\text { bersama keluarga akibat pekerjaan. }\end{array}$ & 31 & 10 & 1 & 5 & 3 & 1,78 & Sangat Tidak Baik \\
\hline 4 & $\begin{array}{l}\text { Terlalu fokus dengan posisi jabatan } \\
\text { menyebabkan saya mengabaikan tanggung } \\
\text { jawab dalam bermasyarakat. }\end{array}$ & 32 & 9 & 3 & 2 & 4 & 1,74 & Sangat Tidak Baik \\
\hline 5 & $\begin{array}{l}\text { Saya mendapat teguran dari kelurga akibat } \\
\text { terlalu loyal terhadap pekerjaan sehingga } \\
\text { terkadang lupa akan tanggung jawab terhadap } \\
\text { keluarga. }\end{array}$ & 31 & 12 & 0 & 3 & 4 & 1,74 & Sangat Tidak Baik \\
\hline & Rata-rata skor & & & & & & 1,93 & \\
\hline
\end{tabular}

Sumber: data diolah, 2020 
Berdasarkan Tabel 3 dapat dilihat bahwa seluruh penilaian katagori seluruh pernyataan kuesiner termasuk dalam katagori setuju dengan skor rata-rata sebesar 3,78. Kriteria jawaban yang memperoleh nilai rata-rata tertinggi terdapat dalam pernyataan no. 1 nilai rata-rata sebesar 3,86 yang menyatakan Saya sering membawa pekerjaan di kantor pulang kerumah. Kriteria jawaban dengan nilai rata-rata terendah terdapat pada pernyataan no. 4 nilai rata-rata sebesar 3,60 yang menyatakan Saya bekerja sesuai jobdesk dan mampu mempertanggung jawabkan kepada atasan.

\section{Tabel 3. Deskripsi Variabel Stres Kerja}

\begin{tabular}{|c|c|c|c|c|c|c|c|}
\hline \multirow{2}{*}{ Pernyataan } & \multicolumn{5}{|c|}{ Jawaban } & \multirow{2}{*}{$\begin{array}{l}\text { Rata-rata } \\
\text { skor }\end{array}$} & \multirow{2}{*}{$\begin{array}{l}\text { Kategori } \\
\text { penilaian }\end{array}$} \\
\hline & 1 & 2 & 3 & 3 & 5 & & \\
\hline Saya sering membawa pekerjaan di kantor pulang kerumah & 9 & 1 & 2 & 14 & 24 & 3,86 & Baik \\
\hline $\begin{array}{l}\text { Saya dapat menyelesaikan pekerjaan lebih banyak jika } \\
\text { diberi waktu lebih lama }\end{array}$ & 10 & 1 & 3 & 16 & 20 & 3,7 & Baik \\
\hline $\begin{array}{l}\text { Jarang diberikan pujian/penghargaan saat menyelesaikan } \\
\text { pekerjaan dengan baik }\end{array}$ & 9 & 4 & 3 & 14 & 20 & 3,64 & Baik \\
\hline $\begin{array}{l}\text { Saya bekerja sesuai jobdesk dan mampu mempertanggung } \\
\text { jawabkan kepada atasan }\end{array}$ & 10 & 5 & 1 & 13 & 21 & 3,6 & Baik \\
\hline
\end{tabular}

Sumber: data diolah, 2020

Berdasarkan Tabel 4 dapat dilihat bahwa seluruh penilaian katagori seluruh pernyataan kuesiner termasuk dalam katagori setuju dengan skor rata-rata sebesar 3,72. Kriteria jawaban dengan nilai rata-rata tertinggi terdapat dalam pernyataan no. 1 nilai rata-rata sebesar 4,02 yang menyatakan bahwa Semua pekerjaan sudah dapat diselesaikan dengan baik dan dapat di pertanggung jawabkan. Kriteria jawaban responden dengan nilai rata-rata terendah terdapat dalam pernyataan no. 6 nilai rata-rata sebesar 3,42 yang meyatakan bahwa Karyawan mempunyai komitmen kerja dan tanggung jawab terhadap instasi perusahaan.

Tabel 4. Deskripsi Variabel Kinerja Karyawan

\begin{tabular}{|c|c|c|c|c|c|c|c|c|}
\hline \multirow{2}{*}{ No } & \multirow{2}{*}{ Pernyataan } & \multicolumn{5}{|c|}{ Jawaban } & \multirow{2}{*}{$\begin{array}{c}\text { Rata-rata } \\
\text { skor }\end{array}$} & \multirow{2}{*}{$\begin{array}{l}\text { Kategori } \\
\text { penilaian }\end{array}$} \\
\hline & & 1 & 2 & 3 & 4 & 5 & & \\
\hline 1 & $\begin{array}{l}\text { Semua pekerjaan sudah dapat diselesaikan dengan baik } \\
\text { dan dapat di pertanggung jawabkan }\end{array}$ & 5 & 0 & 4 & 21 & 20 & 4,02 & Baik \\
\hline 2 & $\begin{array}{l}\text { Saya dapat menyelesaikan pekerjaan dengan cepat dan } \\
\text { dapat menyelesaikan beberapa pekerjaan dalam suatu } \\
\text { waktu tertentu }\end{array}$ & 1 & 1 & 11 & 26 & 11 & 3,9 & Baik \\
\hline 3 & $\begin{array}{l}\text { Selalu dapat menyelesaikan pekerjaan dengan tepat } \\
\text { waktu }\end{array}$ & 3 & 4 & 9 & 19 & 15 & 3,78 & Baik \\
\hline 4 & $\begin{array}{l}\text { Karyawan selalu melaksanakan tugas/pekerjaan secara } \\
\text { efektif }\end{array}$ & 6 & 2 & 6 & 24 & 12 & 3,68 & Baik \\
\hline 5 & $\begin{array}{l}\text { Karyawan harus dapat mengambil keputusan sendiri } \\
\text { atas pekerjaan yang dijalankan }\end{array}$ & 7 & 2 & 8 & 25 & 8 & 3,5 & Baik \\
\hline \multirow[t]{2}{*}{6} & $\begin{array}{l}\text { Karyawan mempunyai komitmen kerja dan tanggung } \\
\text { jawab terhadap instasi perusahaan }\end{array}$ & 8 & 5 & 9 & 14 & 14 & 3,42 & Baik \\
\hline & Rata-rata skor & & & & & & 3,72 & \\
\hline
\end{tabular}

Sumber: data diolah, 2020

Hasil pengujian uji normalitas pada Gambar 2 menunjukkan bahwa titik-titik berada tidak jauh dari garis diagonal. Hal ini berarti bahwa model regresi tersebut sudah berdistribusi normal. 


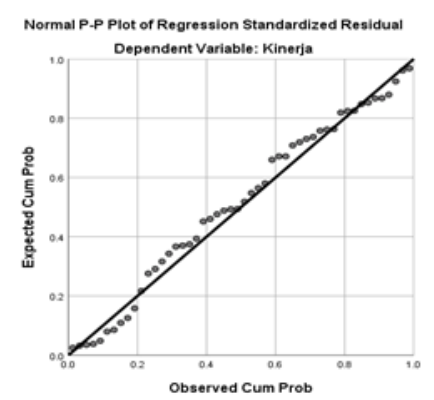

\section{Gambar 2 Hasil Uji Normalitas}

Berdasarkan Gambar 3, dilihat gambar grafik Scatterplot. Hasil gambar tidak membentuk pola teratur dan titik-titik menyebar dibawah dan diatas titik origin (angka 0). Hal ini menunjukan bahwa tidak terjadi heteroskedastis, sehingga model regresi layak dipakai.

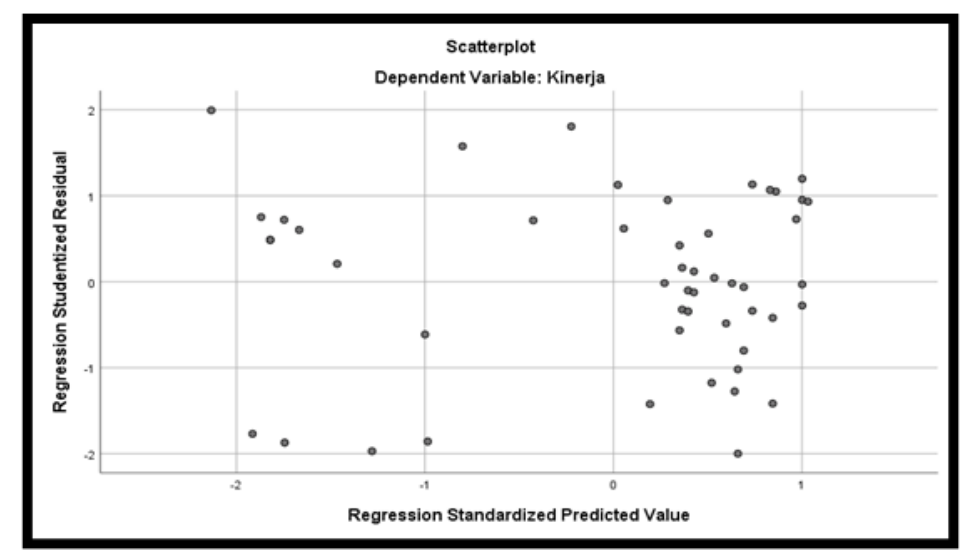

\section{Gambar 3 Hasil Uji Heteroskedastisitas}

Berdasarkan Tabel 5 nilai tolerance work family conflict (X1) dan stres kerja (X2) sebesar 0,608, sedangkan nilai VIF (varian inflation factor) variabel work family conflict (X1) dan stres kerja (X2) sebesar 1,645. Nilai tolerance dan VIF variabel dalam kasus ini sama, maka pada model regresi yang terbentuk tidak terjadi gejala multikolinieritas.

\section{Tabel 5. Hasil Uji Multikolinearitas}

\begin{tabular}{lcc}
\hline \multicolumn{1}{c}{ Variabel } & VIF & Tolerance \\
\hline Work Family Conflict & 1.645 & 0.608 \\
Stres Kerja & 1.645 & 0.608 \\
\hline
\end{tabular}

Sumber : data diolah, 2020

Pengujian hipotesis dilakukan dengan analisis regresi linier barganda untuk menguji hipotesis yang diajukan. Berdasarkan Tabel 5 dapat dibuat persamaan regresi penelitian ini adalah $\mathrm{Y}=16,027-0,088 \mathrm{X} 1+0,481 \mathrm{X} 2+\varepsilon \mathrm{i}$. Interprestasi dari koefisien regresi adalah $\beta 0=16,027$, secara statistik menunjukan bahwa kinerja karyawan akan meningkat sebesar 16,027 persen dengan syarat variabel lain dalam penelitian ini yakni work family conflict (X1), dan stres kerja (X2) diasumsikan sama dengan nol. $\beta 1=-0,088$, secara statistik menunjukkan ada pengaruh negatif 
antara variabel work family conflict (X1) terhadap kinerja karyawan (Y) sebesar -0,088 yang artinya setiap terjadi (adanya) peningkatan work family conflict sebesar satu satuan maka akan menyebabkan menurunnya kinerja karyawan sebesar -0,088 persen dengan syarat variabel lain diasumsikan sama dengan nol. $\beta 2=0,481$, secara statistik menunjukkan ada pengaruh positif antara variabel stres kerja (X2) terhadap kinerja karyawan (Y) sebesar 0,481 yang artinya setiap terjadi kenaikan (adanya) stres kerja sebesar satu satuan maka akan menyebabkan meningkatanya KinerjaKaryawan sebesar 0,481 persen dengan syarat variabel lain diasumsikan sama dengan nol.

\section{Tabel 5 Hasil Analisis Regresi Linear Berganda}

\begin{tabular}{|c|c|c|c|c|c|c|}
\hline \multicolumn{7}{|c|}{ Coefficients $^{a}$} \\
\hline \multirow{2}{*}{\multicolumn{2}{|c|}{ Model }} & \multicolumn{2}{|c|}{$\begin{array}{l}\text { Unstandardized } \\
\text { Coefficients }\end{array}$} & \multirow{2}{*}{$\begin{array}{c}\begin{array}{c}\text { Standardized } \\
\text { Coefficients }\end{array} \\
\text { Beta } \\
\end{array}$} & \multirow[t]{2}{*}{$\mathrm{T}$} & \multirow[t]{2}{*}{ Sig. } \\
\hline & & $\mathrm{B}$ & Std. Error & & & \\
\hline \multirow{3}{*}{1} & (Constant) & 16.027 & 3.507 & & 4.570 & .000 \\
\hline & Work family conflict & -.088 & .178 & -.076 & -.496 & .622 \\
\hline & Stress Kerja & .481 & .143 & .519 & 3.377 & .001 \\
\hline
\end{tabular}

a. Dependent Variable: Kinerja

Sumber : data diolah, 2020

Tabel 6 Hasil Analisis Koefisien Determinasi

Model Summary ${ }^{\mathrm{b}}$

\begin{tabular}{cccccc}
\hline Model & $\mathrm{R}$ & R Square & $\begin{array}{c}\text { Adjusted } \mathrm{R} \\
\text { Square }\end{array}$ & $\begin{array}{c}\text { Std. Error of the } \\
\text { Estimate }\end{array}$ & $\begin{array}{c}\text { Durbin- } \\
\text { Watson }\end{array}$ \\
\hline 1 & $.570^{\mathrm{a}}$ & .325 & .296 & 4.156 & 1.539 \\
\hline
\end{tabular}

Sumber : data diolah, 2020

Berdasarkan Tabel 6, koefisien determinasi yang ditunjukkan dari nilai R Square dapat dilihat bahwa koefisien determinasi sebesar 0.352 atau $35.2 \%$ yang artinya variasi hubungan antara work family conflict dan stres kerja terhadap kinerja karyawan adalah sebesar 35.2\% sedangkan sisanya $64.8 \%$ ditentukan oleh variabel lain di luar work family conflict dan stres kerja yang tidak dibahas dalam penelitian ini.

Uji statistik-t pada dasarnya menunjukkan seberapa jauh pengaruh satu variabel penjelas/independen digunakan untuk menguji hipotesis $\mathrm{H} 1, \mathrm{H} 2$, yaitu pengaruh secara parsial variabel work family conflict dan stres kerja terhadap kinerja karyawan pada PT. BPR Partakencana Tohpati Di Denpasar.

1. Pengaruh work family conflict terhadap kinerja karyawan pada PT. BPR Partakencana Tohpati di Denpasar

Dari Tabel 5 hasil penelitian diketahui adanya pengaruh negatif work family conflict terhadap kinerja karyawan pada PT. BPR Partakencana Tohpati di Denpasar. Hal ini dibuktikan dengan t-hitung $=-0,496$ dibandingkan dengan nilai t-tabel $=2,000$, maka ternyata nilai $\mathrm{t}$-hitung lebih kecil dari nilai t-tabel, dan t-hitung berada pada daerah penolakan H0. Dengan demikian H0 
ditolak dan H1 diterima. Ini berarti bahwa secara statistik untuk uji satu sisi pada taraf kepercayaan $(\alpha)=5 \%$, secara parsial work family conflict (X1) berpengaruh negatif terhadap kinerja karyawan (Y). Artinya jika terjadi peningkatan work family conflict (X1) akan menurunkan kinerja karyawan (Y). Dengan demikian hipotesis yang menyatakan bahwa work family conflict (X1) berpengaruh negatif terhadap kinerja karyawan (Y) teruji kebenarannya. Hal ini mengindikasikan bahwa seluruh indikator yang terdapat pada pernyataan kuisioner variabel work family conflict mampu mempengaruhi kinerja karyawan pada PT. BPR Partakencana Tohpati di Denpasar. Hasil penelitian ini juga mendukung penelitian sebelumnya yang dilakukan oleh Jackson dan Yohanes Arianto (2017) yang menyatakan bahwa work family conflict berpengaruh negatif terhadap kinerja karyawan.

2. Pengaruh Stres Kerja terhadap Kinerja Karyawan pada PT. BPR Partakencana Tohpati di Denpasar

Dari Tabel 5 hasil penelitian diketahui adanya pengaruh positif dan signifikan stres kerja terhadap kinerja karyawan pada PT. BPR Partakencana Tohpati di Denpasar. Hal ini dibuktikan dengan t-hitung $=3,377$ dibandingkan dengan nilai t-tabel $=2,000$, maka ternyata nilai thitung lebih besar dari nilai t-tabel, dan t-hitung berada pada daerah penolakan H0. Dengan demikian H0 ditolak dan H2 diterima. Ini berarti bahwa secara statistik untuk uji satu sisi pada taraf kepercayaan $(\alpha)=5 \%$, secara parsial stres kerja (X2) berpengaruh positif terhadap kinerja karyawan (Y). Artinya jika terjadi peningkatan stres kerja (X2) akan meningkatkan kinerja karyawan (Y). Dengan demikian hipotesis yang menyatakan bahwa stres kerja (X2) berpengaruh positif terhadap kinerja karyawan (Y) teruji kebenarannya.

Berdasarkan penelitian dari Pranoto (2013) tentang pengaruh kecerdasan emosial dan stres kerja terhadap kinerja karyawan di Dinas Kebudayaan dan Pariwisata provinsi Jawa Tengah, menyatakan bahwa stres maupun tidak stres karyawan tetap dapat bekerja dengan baik dan tidak ada penurunan kinerja..Sejalan dengan penelitian Pranoto (2013) tersebut, dalam penelitian ini ditemukan bahwa stres kerja memberikan pengaruh yang positif dan signifikan terhadap kinerja karyawan. Berdasarkan hasil wawancara singkat dengan karyawan PT. BPR Partakencana Tohpati menunjukkan bahwa walaupun adanya stres kerja yang dirasakan oleh karyawan tidak memberikan pengaruh terhadap kinerja karyawan. Salah satu contohnya adalah karyawan merasa pekerjaannya sudah menjadi suatu kebiasaan yang dilakukan sehari-hari. Sehingga karyawan PT. BPR Partakencana Tohpati sudah terbiasa dan dapat mengatasi permasalahan stres kerja agar tidak mengganggu pekerjaan mereka. 
Tabel 7 hasil uji menunjukkan bahwa work family conflict dan stres kerja berpengaruh positif dan signifikan terhadap kinerja karyawan pada PT. BPR Partakencana Tohpati di Denpasar. Hal ini dibuktikan dengan nilai F-tabel sebesar 3,15 dan nilai F-hitung sebesar 11,309, sehingga jika dibandingkan nilai F-hitung lebih besar dari F-tabel dan F-hitung berada pada daerah penolakan $\mathrm{H} 0$ maka H3 diterima. Ini berarti bahwa work family conflict (X1) dan stres kerja (X2) berpengaruh secara simultan terhadap kinerja karyawan (Y). Dengan demikian hipotesis yang menyatakan bahwa work family conflict (X1) dan stres kerja (X2) berpengaruh terhadap kinerja karyawan (Y) teruji kebenarannya.

\section{Tabel 10 Hasil Uji F}

\begin{tabular}{|c|c|c|c|c|c|c|}
\hline \multicolumn{2}{|c|}{ Model } & \multirow{2}{*}{$\frac{\text { Sum of Squares }}{390.676}$} & Df & Mean Square & \multirow{2}{*}{$\frac{\mathrm{F}}{11.309}$} & \multirow{2}{*}{$\frac{\text { Sig. }}{.000^{\mathrm{b}}}$} \\
\hline & Regression & & 2 & 195.338 & & \\
\hline 1 & Residual & 811.824 & 47 & 17.273 & & \\
\hline & Total & 1.202 .500 & 49 & & & \\
\hline
\end{tabular}

a. Dependent Variable: Kinerja

b. Predictors: (Constant), Stress_Kerja, Work_family_conflict

Sumber : data diolah, 2020

\section{Simpulan}

Berdasarkan data yang diperoleh dari hasil analisis dapat ditarik kesimpulan bahwa, work family conflict berpengaruh negatif terhadap kinerja karyawan pada PT. BPR Partakencana Tohpati di Denpasar. Artinya, jika terjadi peningkatan work family conflict maka akan dapat menurunkan kinerja karyawan pada PT. BPR Partakencana Tohpati di Denpasar. Stres kerja berpengaruh positif dan signifikan terhadap kinerja karyawan pada PT. BPR Partakencana Tohpati di Denpasar. Artinya, jika terjadi peningkatan stres kerja maka akan dapat mempengaruhi kinerja karyawan pada PT. BPR Partakencana Tohpati di Denpasar. Work family conflict dan stres kerja berpengaruh positif dan signifikan terhadap kinerja karyawan pada PT. BPR Partakencana Tohpati di Denpasar. Ini berarti bahwa apabila terdapat work family conflict dan stres kerja dapat mempengaruhi kinerja karyawan pada PT. BPR Partakencana Tohpati di Denpasar.

Beberapa hal yang bisa disarankan dari hasil penelitian ini, adalah banyaknya tuntutan tugas yang diberikan kepada karyawan agar tidak menimbulkan work family conflict maka bagi pihak karyawan dihimbau untuk menyelesaikan tugas tepat pada waktunya. Sehingga, meskipun diberikan tugas yang bersifat deadline karyawan dapat menyelesaikannya sesuai dengan waktunya. Bagi pihak manajemen, sebaiknya dianjurkan agar tidak menyita waktu libur karyawan untuk menyelesaikan tugas kantor karena jika hal tersebut sering terjadi maka akan menimbulkan rasa jenuh pada karyawan yang akan mengganggu kinerja serta menghasilkan hasil kinerja yang kurang 
memuaskan. Stress kerja berpengaruh positif terhdap kinerja karyawan maka disarankan sebaiknya perusahaan lebih memperhatikan karyawannya untuk mengurangi stress kerja melalui penyesuaian beban pekerjaan dengan tingkat kemampuan keryawan sehingga kinerja tetap mengalami peningkatan. Dalam meningkatkan kinerja karyawan, perlu adanya pembenahan pada diri karyawan masing-masing yaitu pembenahan dalam kepribadian karyawan dalam bekerja seperti bekerja sesuai dengan SOP yang berlaku di perusahaan, sehingga meminimalisir penyimpangan yang terjadi dalam bekerja. Bagi penelitian mendatang disarankan agar dapat memodifikasi penelitian ini dengan menambah atau mengembangkan variabel serta indikator lain yang berpengaruh terhadap kinerja karyawan, dan perlunya dilakukan penelitian kembali untuk mengetahui pengaruh kinerja karyawan setelah dipengaruhi oleh work family conflict dan stres kerja.

\section{Daftar Pustaka}

A.A. Anwar Prabu Mangkunegara (2010). Evaluasi Kinerja SDM, PT.Refika Aditama, Bandung.Bngun, Wilson,2012, Manajemen Sumber Daya Manusia, Erlangga, Bandung Abdullah.2013. Inovasi Pembelajaran. Bumi Aksara. Jakarta.

Abedul Ghofur Anshori. 2008. Penerapan Prinsip Syariah Dalam Lembaga Pembiayaan dan Perusahaan Pembiayaan. Yogyakarta: Pustaka Pelajar

Abidin, Yanus. (2010). Strategi Membaca: Teori dan Pembelajarannya. Bandung: Rizqi Press. Agus Fauzul Hakim, 2015. Kejadian Luar Biasa Demam Berdarah di Jawa Timur http://health.kompas.com. Diakses tanggal 26 Februari 2016.

Agusty, Ferdinand. 2006. Metode Penelitian Manajemen: Pedoman Penelitian Untuk skripsi, Tesis dan Disertai Ilmu Manejemen. Semarang: Universitas Dipenegoro.

Ahmad, Susanto. (2013). Teori Belajar dan Pembelajaran di Sekolah Dasar. Jakarta: Kencana Prenada Media Group.

Al Hakim, S., dkk. 2016. Implementasi Kebijakan Remunerasi Dalam Meningkatkan Kinerja Pegawai Negeri Sipil (PNS) di Fakultas Ilmu Sosial Universitas Negeri Malang. Jurnal Ilmiah Administrasi Publik (JIAP) Vol. 2 No. 3 (2016) hal. 64-72.

Amelia (2010). Pengaruh Moel Pembelejaran Generatif terhadap Kemampuan Koneksi Matematis Siswa. (Skripsi). UIN Syarif Hidayatullah, Jakarta.

Bambang Wahyudi. (2010). Manajemen Sumber Daya Manusia. Jakarta:Sulita.

Bangun, Wilson. 2012. Manajemen Sumber Daya Manusia. Jakarta: Erlangga.

Carr A. C., and Frei B. (2013) Toward a new recommended dietary allowance for vitamin C based on antioxidant and health affect in humans. Am. J. Clin. Nutr. 69. 1086-1107

Dedy Setyawan. Pengaruh Work Family Conflict, Stres Kerja Dan Kepuasan Kerja Terhadap Kinerja Karyawan (Studi pada Karyawan Wanita PT. Putra Tunas Subur Pacitan). Prodi Manajemen Universitas Muhammadiyah Yogyakarta. 2017.

Edwin B Flippo, 2012, Personal Management (Manajemen Personal), Edisi. VII Jilid II, Terjemahan Alponso S, Erlangga, Jakarta

Fahmi,Irham. 2010. Manajemen Risiko. Bandung Alfabeta.

Gaol, CHR. Jimmy L, 2014. A to Z Human Capital (Manajemen Sumber Daya Manusia) Konsep, Teori, dan Pengembangan Dalam Konteks Organisasi Publik dan Bisnis, PT. Gramedia Widiasarana, Jakarta. 
Ghozali, Imam. 2012. Aplikasi Analisis Multivariate dengan Program INM SPSS. Yogyakarta: Universitas Dipeonogoro

Hellriegel dan Slocum. 2014. Organizational Behavior $13^{\text {th }}$ editon. South-Wastern Cangage Learning: USA.

Ida Ayu Putu Widani Sugianingrat, I Wayan Gde Sarmawa, Anak Agung Dwi Widyani.2017. Pengaruh Work Family Conflict Dan Stres Terhadap Kinerja Karyawan Lembaga Perkreditan Desa Di Kabupaten Tabanan. Prosiding Seminar Nasional Hasil Penelitian Denpasar, 30 September 2017. Universitas Hindu Indonesia.

Istomo. 2013. Hubungan Antara Komposisi, Struktur dan Penyebaran Ramin Studi Kusus di Areal HPH PT. Inhutani III Kalimantan Tengah. Tesis. IPB Press. Bogor.

Jackson dan Yohanes Arianto. 2017. Pengaruh Work Family Conflict Terhadap Kinerja Karyawati PT Sinta Pertiwi. ISSN : 2339 - 0689, E-ISSN : 2406-8616. J.Kreatif, Vol.5, No.1, Oktober 2017. Universitas Pamulang.

Jane Yolanda Roboth, 2015 dalam Jurnal Analisis Work Family Conflict Dan Kinerja Wanita Berperan Ganda Pada Yayasan Comparisson East Indonesia

Kayo, E. A. (2016). Sektor keuangan (8) _ Saham OK. Retrieved From http://www.sahamok.com/emiten/sektor-keuangan/

Luthans, Fred. 2014. Prilaku Organisasi, (Alih Bahasa V.A Yuwono, dkky), Edisi Bahasa Indonesia, Yogyakarta.

Mahmudi. 2010. Manajemen Kinerja Sektor Publik. Jakarta.STIE YKPN.

Ni Wayan Mega Sari Apri Yani, I Gde Adnyana Sudibya, Agoes Ganesha Rahyuda. Pengaruh Work Family ConflictDan Stres Kerja Terhadap Kepuasan Kerja Dan Turnover Intention Karyawan Wanita pada Bank Rakyat Indonesia (BRI). E-Jurnal Ekonomi dan Bisnis Universitas Udayana 5.3 2016. ISSN : 2337 - 3067.

Novitasari, R. W, dkk. (2015). Assessment Nyeri. Yogyakarta: Fakultas Kedokteran Universitas Gajah Mada.

Rantika, Renny. 2011.Pengaruh Konflik Kerja Keluarga Terhadap Komitmen Organisasional yang Dimediasi oleh Kepuasan Kerja pada Profesi Perawat di Rumah Sakit Umum Daerah (RSUD) Dr. Moewardi Surakarta. Jurnal. Bandung: Fkultas Ekonomi, Universitas Kristen Moranatha.

Robbins, Stehen P. \& A. Judge, Timothy (2011) Organizational Brhavior. Fourteent Edition. Pearson education. New Jersey 07458. 77-89

Ruderman, E., \& Tambar, S. (2012). Rheumatoid arthritis. Atlanta : American College of Rheumatology.

Salam, S.O. (2010). Job Stress and Counterproductive Work Behavior: Negative Affective as a Moderator. The Social Science, 5 (6), hal.468-492.

Sedamayanti. 2011. Manajemen Sumber Daya Manusia, Reformasi Birokrasi dan Manajemen Pegawai Negeri Sipil (cetakan kelima). PT Refika Aditama. Bandung

Sekaran, Uma, (2006), Metodologi Penelitian Untuk Bisnis Buku 2 Edisi 4, Jakarta: Salemba Empat

Simamora, Roymond. (2010). Buku Ajar Manajemen Keperawatan. Jakarta: EGC.

Soeharto, Prawirokusumo. (2010). Kewirausahaan Dan Manajemen usaha Kecil (Edisi 1). Jpgjakarta: BPFE

Sudibya, T. 2018. Pertolongan Pertama pada Balita, (online), http://tantisudbya.blogspot.com/ 2018/03/pertolongan-pertama-pada-balita.htlm yang diakses pada 16 Oktober 2018, pkl.15.00

Sugiyono (2015). Metode Penelitian Kombinasi (Mix Methods). Bandung: Alfabeta.

Suryani, N. K., \& Maha Yoga, G. A. D. (2018). Konflik Dan Stres Kerja Dalam Organisasi. Widya Manajemen, 1(1), 99-113. https://doi.org/10.32795/widyamanajemen.v1i1.209 
Welim, M. F., \& Ch. Rusiti. (2013). Pengaruh Kepemilikan Manajerial Dan Kepemilikan Institutional Terhadap Nilai Perusahaan (Studi Empiris Pada Perusahaan Perbankan Yang Terdaftar Di BEI), 1-14.

Wirakristama, Richardus Chandra, Suharnomo. 2011. Analisis Konflik Peran Ganda (WorkFamily Conflict) Terhadap Kinerja Karyawan Wanita Pada PT Nyonya Menner Semarang Dengan Stres Kerja Sebagai Variabel Intervening. Universitas Dipenegoro. Semarang. 